\title{
Immunoregulatory Role of MicroRNA-21 in Macrophages in Response to Bacillus Calmette-Guerin Infection Involves Modulation of the TLR4/MyD88 Signaling Pathway
}

Xin Xue ${ }^{a, b}$ Yi Qiuc Hong-Li Yang ${ }^{d}$

aDepartment of Pathogen Biology \& Immunology, Xi'an Jiaotong University Health Science center, Xi'an, ${ }^{b} T h e$ Fourth internal medicine, Xi'an Chest Hospital, Xi'an, 'The Second internal medicine, Xi'an Chest Hospital, Xi'an, dDepartment of Gastroenterology, Qianfoshan Hospital of Shandong Province, Jinan, P.R. China 